\title{
La Ley 19.496 como un supuesto de descodificación material y su relación con las leyes especiales a las que alude el artículo 2 bis
}

\author{
Act 19.496 as an event of material decoding and its relation \\ to the special laws referred to in article 2 bis
}

\author{
Iñigo de la Maza Gazmuri \\ Universidad Diego Portales, Chile \\ Hernán Cortez López \\ Universidad Diego Portales, Chile
}

\section{RES UMEN}

Si bien la Ley 19.496 constituye uno de los casos más importantes de descodificación material a nivel nacional, dicha característica corre el riesgo de perder toda importancia atendida la proliferación de otras leyes que regulan mercados específicos en los que también se ven involucrados consumidores, además de la importancia que se asigna al Código Civil como derecho común y supletorio en materia de contratos. Este trabajo pretende, por un lado, dar cuenta de estos riesgos, y, por otro, descartar que estos se hayan manifestado, considerando la preeminencia de la Ley del Consumidor en la jurisprudencia al aplicar el artículo 2 bis de la Ley 19.496.

\section{PALABRAS CLAVE}

Ley $19.496 \cdot$ principio de especialidad normativa $\cdot$ leyes especiales.

\section{A B S T RACT}

Although in Chile the Act 19.496 is one of the most important cases of material decoding, this trait risks losing all importance provide the proliferation of other Acts that norm specific markets involving consumers, besides the importance assigned to the Civil Code as Common and supplementary law regarding contracts. This work intends, on the one hand, give notice of these risks, and on the other, discard they have manifested themselves, taking into account the pre-eminence of the Consumer Law in judicial decisions when applying article 2 bis of the Act 19.496 . 
Act $19.496 \cdot$ lex specialis principle $\cdot$ special rules.

\section{INTRODUCCIÓN}

En un sentido que precisaremos, la Ley 19.496 sobre Protección de los Derechos de los Consumidores (LPC) configura un supuesto de descodificación material respecto del Código Civil. La materialidad de esta descodificación se explica pues se abandona una de las asunciones estructurales del Código Civil que vamos a denominar igualdad formal, reemplazándola por otra -inversa - que llamaremos desigualdad formal. En virtud de este movimiento, la LPC abandona la neutralidad del Código Civil frente a las partes y opta por la tutela de una de ellas (el consumidor) en desmedro de la otra (el proveedor). Se trata de un supuesto de descodificación muy semejante al del derecho laboral.

Junto a la LPC existe un frondoso grupo de leyes que, por una parte, también se ha descodificado del Código Civil y que, por otra, disciplinan ámbitos que involucran masivamente relaciones de consumo. La pregunta en torno a la que se estructura este trabajo es si la descodificación material que se logró a través de la LPC corre el riesgo de vaciarse o, al menos, diluirse de manera muy relevante a través de estas otras leyes especiales.

Ese riesgo puede verificarse de dos maneras. La primera es que, como tanto la LPC como estas otras leyes son especiales respecto del Código Civil, dichas leyes (aquellas diversas de la LPC) tengan como ley general de referencia inmediata al Código Civil. Si es de esta manera, en los vacíos que dejen esas leyes se aplicará el Código Civil y la idea de igualdad formal que lo impregna. La segunda manera en que puede verificarse el riesgo al que aludimos es que, aun si esas leyes tienen como ley general de referencia inmediata a la LPC, contengan disposiciones especiales que, por una parte, determinen su aplicación preferente respecto de la LPC y, por otra, esas disposiciones especiales devalúen la protección que prodiga la LPC a los consumidores.

La tesis que defendemos en este trabajo es que ninguno de esos dos riesgos se ha materializado y que, por ahora al menos, la descodificación material conseguida a través de la LPC goza de buena salud.

En primer lugar, si bien es cierto que la LPC es especial respecto del derecho común, debe considerarse como general respecto de las otras leyes que disciplinan ámbitos que involucran relaciones de consumo. De esta manera, respecto de esas leyes, la ley general de referencia inmediata es la LPC y, únicamente en lo que esta no disciplina, el Código Civil que, por lo mismo, sería una ley general de referencia mediata. 
En segundo lugar, si bien por disposición del artículo 2 bis de la LPC estas leyes se aplican con preferencia a la LPC, un examen de las decisiones de los tribunales superiores muestra un claro predominio de la LPC, aun existiendo dichas leyes. Lo que esto muestra es que dichas leyes, en general, carecen de disposiciones que devalúen la tutela que prodiga la LPC a los consumidores.

Si las tesis que defendemos son correctas, entonces no cabe duda de que la LPC es, actualmente, una de las leyes más relevantes en la disciplina de las relaciones patrimoniales entre privados y, por lo mismo, hay muy buenas razones para tomársela extremadamente en serio, por la doctrina, desde luego, pero, sobre todo, por el legislador y los jueces.

Estas son las ideas; el orden en que las abordaremos es el siguiente. En primer lugar, presentamos algunas nociones respecto de la descodificación que supuso la LPC. A continuación, describimos los dos riesgos que enfrenta esta descodificación. En tercer lugar, mostramos que la LPC es la ley general de referencia inmediata respecto de otras que disciplinan ámbitos en los que se presentan relaciones de consumo. Finalmente, en cuarto lugar, exponemos el predominio de la LPC por sobre las leyes especiales y damos cuenta de algunas excepciones.

\section{Descodificación y Ley de Protección de los Derechos de los Consumidores}

El profesor Corral ha sugerido que la expresión descodificación es polisémica. ${ }^{\mathrm{I}}$ Tiene razón, y atendida la importancia de la expresión para este trabajo resultará conveniente precisar el sentido en el que la emplearemos.

Aludiendo a lo que podría denominarse una «huida de la codificación», IRTI se ha referido a un "proceso de consolidación y nacimiento de microsistemas»; ${ }^{2}$ "microsistemas de normas, con lógicas propias y autónomas». ${ }^{3}$ Es en ese preciso sentido, es decir, como un proceso de nacimiento y consolidación de sistemas de normas con lógicas propias y autónomas, en que empleamos la expresión descodificación.

Se trata de una idea muy seductora, aunque sujeta a ciertas cualifica-

${ }^{1}$ Corral, Hernán, La descodificación del Derecho Civil en Chile, en La descodificación del Derecho Civil en Chile, en El Código Civil de Chile (I855-2005). Trabajos expuestos en el Congreso Internacional celebrado para conmemorar su promulgación (Santiago, 3-6 de octubre de 2005), ahora en Guzmán Brito, Alejandro (editor), LexisNexis (Santiago, 2007) pp. 64I-65I.

${ }^{2}$ IrTI, Natalino, La edad de la descodificación (Editorial Bosch, s.l., I992) p. 30.

${ }^{3}$ IRTI, Natalino, cit. (n. 2) p. 32. 
ciones. Como veremos, una de esas cualificaciones ha sido aludida por Alejandro GuZMÁn Brito, quien ha sugerido cierta cautela frente a esta idea de descodificación en cuanto dichos microsistemas de normas relegarían al Código Civil a una función residual. GuZMÁn BRITo ha criticado a IRTI, pues no habría distinguido "entre la descodificación meramente formal a través de las leyes especiales que en lugar de arrinconar el Código, lo suponen y lo necesitan; y la descodificación material, que se produce cuando se dictan no solo las leyes especiales sino singulares, es decir, que parten de lógicas o valores opuestos a los del Código (en tal sentido la única que habría sucedido en nuestro derecho sería el desgajamiento del derecho laboral y el intento frustrado de regular la propiedad con criterios de raigambre socialista a través de las leyes de reforma agraria)». ${ }^{4}$

La crítica nos parece correcta y, desde luego, útil para lo que nos interesa desarrollar en este trabajo. Sobre dicha crítica convienen un par de comentarios.

El primero de ellos es que, respecto de lo que GuZmán Brito denomina «descodificación material» habría que sumar al derecho laboral la LPC. Según nuestra comprensión, lo que el profesor denomina «descodificación material» es un fenómeno en virtud del cual ciertas leyes no solo se alejan, por así decirlo, «geográficamente» del Código Civil, sino que, además, en términos valóricos. En nuestra opinión, esto es precisamente - y de manera tan conspicua como sucede en el derecho laboral- lo que acontece tratándose de la LPC. El fenómeno ha sido advertido en múltiples ocasiones ${ }^{5}$ y volveremos sobre él a propósito de nuestra cualificación acerca de la descodificación.

El segundo comentario respecto a las ideas de GuzMán BRITo sobre descodificación es relativo a la descodificación material. Como hemos visto, se produce cuando las leyes especiales son «singulares», es decir, según lo entiende Guzmán BRITo, cuando parten de lógicas o valores opuestos al Código. Pues bien, lo que nos interesa comentar aquí es que en los supuestos de descodificación material resulta conveniente prestar atención a cuáles son esas lógicas o valores opuestos al Código. La razón es que, según nos parece, esas lógicas o valores nunca son radicalmente opuestas al Có-

${ }^{4}$ Guzmán Brito, et al., De la codificación a la descodificación (Santiago, Ediciones Universidad Diego Portales, 2006) p. 42.

5 En este sentido puede mencionarse a: Kemelmajer Carlucci, Aída, Los dilemas de la responsabilidad civil, en Revista Chilena de Derecho 28 (200I) 44, p. 677 y FigueroA YÁÑEz, Gonzalo, Codificación, descodificación, recodificación del derecho civil (2005), en Cuadernos de análisis jurídicos, Colección de Derecho Privado II, Universidad Diego Portales, p. I05. 
digo; así, por ejemplo, un contrato de trabajo sigue siendo un "contrato» en los términos del artículo I 438 del Código Civil, y lo mismo sucede con un contrato de adhesión de aquellos disciplinados por la LPC. Entonces, ¿en dónde se encuentra el matiz en el tratamiento cuya intensidad permite hablar de descodificación material?

Según creemos, tratándose del Código Civil, se asume - generalmente, al menos- una noción de igualdad formal entre las partes que se vinculan contractualmente, es decir, una noción de igualdad de corte individualista, abstracta y, por lo mismo, desaprensiva frente a las condiciones materiales de las personas. ${ }^{6}$ Una consecuencia de esa noción de igualdad formal es que, por regla muy general, cuando la validez del contrato se hace depender de consideraciones de justicia, se trata de consideraciones de justicia procedimental, es decir, relativas al proceso de formación del consentimiento, y no sustantiva, o sea, a la justicia de los términos del acuerdo. Ausentes el error, el dolo y la fuerza, la consideración de la justicia de los términos de intercambio es excepcional, limitada a los supuestos de lesión enorme. ${ }^{7}$

Por lo que toca a la LPC o al Código del Trabajo en su regulación del contrato de trabajo, la asunción parece la inversa. ${ }^{8}$ No es que se preste

${ }^{6}$ Ver abundantes citas sobre el tema en Walker Silva, Nathalie, Bases para una deconstrucción del concepto de rescisión por lesión, en Revista Chilena de Derecho 44 (2017) 3, pp. 707-710. Por otra parte, respecto de la noción de igualdad formal, puede consultarse Seco Martínez, José María, De la igualdad formal a la igualdad material. Cuestiones previas y problemas a revisar, en Derechos y Libertades: Revista de Filosofia del Derecho y Derechos Humanos 36 (enero 2017) pp. 55-89.

7 Ver Dítz-Picazo, Luis, Fundamentos del Derecho Civil Patrimonial (Madrid, Editorial Civitas, 6. ${ }^{\text {a }}$ edición, 2007) I, p. 58.

${ }^{8}$ En este sentido, puede consultarse una sentencia del Tribunal Constitucional español del 25 de enero de 1983, según la cual: "De todo ello se deriva el especifico carácter del derecho laboral en virtud del cual [...] se constituye como un ordenamiento compensador e igualador en orden a la corrección, al menos parcialmente, de las desigualdades fundamentales [...] La indicada desigualdad del trabajador se corrige también mediante normas procesales, cuyo contenido expresa diferencias jurídicas que impiden o reducen la desigualdad material y que no pueden recibir una valoración negativa, en la medida en que la desigualdad procesal» establecida aparezca razonablemente ligada a tal finalidad y sea proporcionada a la desigualdad material existente». Según la cita de Fuenmayor, Amadeo, Alcance del principio constitucional de igualdad, en Anuario de derecho civil, 4 (1983), p. I340. Por lo que toca a la desigualdad tratándose de las relaciones disciplinadas por la LPC, conviene prestar atención a algunas sentencias de la Corte Suprema. En las dos primeras - Corte Suprema, rol I00759-2016, 29 de noviembre de 2018 (y de forma muy similar en la sentencia de Corte Suprema, rol 7002-2015, is de mayo de 2016) — se lee lo siguiente: "La normativa instalada por la Ley 19.496 y sus modificaciones, en especial la Ley 19.955, estructuró un sistema de protección al consumidor que modera los principios clásicos de la contratación recepcionados 
atención a las condiciones materiales de las partes en los casos concretos, sino que se asume una noción de desigualdad que podríamos denominar «formal» entre las partes. Es decir, se estima, en abstracto — con desaprensión de sus condiciones materiales concretas- que una de ellas (el consumidor) se encuentra en una posición desmejorada respecto de la otra (el proveedor), y que, por lo mismo, puede aprovecharse de la primera. Por lo mismo, aun cuando no se abandonan las consideraciones de justicia

en los Códigos Civil y de Comercio, particularmente en lo relativo a la formación del consentimiento y a la autonomía de la voluntad en su dimensión de libertad para contratar por parte del proveedor de bienes o servicios y en cuanto a la libre determinación del contenido negocial que trasciende la pura protección de la libertad e igualdad de los contratantes y las consecuencias que envuelve el incumplimiento de deberes contractuales».

En la tercera (Corte Suprema, rol 62I73-2016, 2I de diciembre de 20I7), en tanto: "5. Que en la práctica del ejercicio contractual de esta clase de vinculos obligacionales se verifica en el marco de una situación fáctica caracterizada por una desigualdad entre las partes, la que en muchas ocasiones se traduce en una inequidad por la presencia de antecedentes culturales $o$ técnicos que se traducen en una desproporcionalidad o asimetría económica entre los comparecientes, lo cual puede dar lugar a situaciones a las cuales el legislador consulta diversos mecanismos para disipar sus efectos más perniciosos, entre ellas la norma contemplada en el artículo I6 letra g) de la Ley I9.496 que establece una sanción de ineficacia frente a determinada clase de cláusulas o estipulaciones contenidas en estos contratos, las cuales podrán ser calificadas conceptualmente como abusivas».

En el plano de la dogmática jurídica se han definido a las cláusulas abusivas como «estipulaciones contractuales que entrañan un desequilibrio de las partes en la convención» (WaHL SiLva, Jorge, La protección de los derechos de los consumidores en Chile, Aspectos sustantivos y procesales luego de la reforma contenida en la Ley 19.955 de 2004, ahora en BARAONA, Jorge y Lagos, Osvaldo (editores), La protección de los derechos de los consumidores en Chile, Cuadernos de Extensión Jurídica I2 (Santiago, 2006, Universidad de los Andes, Facultad de Derecho) p. 6o), o aún más precisamente como aquellas estipulaciones que entrañan un «desequilibrio entre las prestaciones del consumidor y el proveedor» (WAHL Silva, Jorge, cit (n. 8) p. 60), asociándose su presencia en los contratos de adhesión a una posición monopólica por parte del proveedor, así como a un mercado que funciona imperfectamente.

$\mathrm{Al}$ respecto el citado profesor Wahl Silva, citado en la mencionada sentencia rol 621732016, advierte que «diversos autores destacan la importancia del llamado problema de la información, conforme al cual la actividad de revisar y comprender un contrato de adhesión no resulta necesariamente racional por parte del consumidor. Acerca de este punto, en la doctrina nacional es muy esclarecedor un estudio publicado por Ínigo de la Maza. Como factores que contribuyen a dicha conducta, el autor citado menciona, entre otros, la dificultad para comprender el lenguaje e incluso, entender los caracteres en que está escrito; la poca disponibilidad de tiempo; la imposibilidad de negociar los términos, incluso porque el agente del proveedor carece de poderes suficientes al efecto; [...] y la confianza en que los tribunales no harán exigibles los eventuales términos injustos del contrato» (Wahl Silva, Jorge, cit. (n. 8) pp. 60 y 6I). 
procedimental, se complementan de manera muy vigorosa con otras de justicia material, tal y como sucede conspicuamente tratándose del control de las condiciones generales. 9

\section{Dos AMENAZAS PARA LA DESCODIFICACIÓN DE LA LEY de Protección de los Derechos de los Consumidores}

Según hemos afirmado en la sección anterior, la LPC constituye un supuesto de descodificación material en la medida en que se aleja de ciertos valores del Código Civil, específicamente de una cierta noción de igualdad — la formal — que parece impregnarlo, desplazándose hacia la noción inversa — una desigualdad formal entre las partes_-, constituyéndose, de manera semejante al derecho laboral, como un cuerpo legal que procura compensar dicha desigualdad protegiendo a la parte más débil.

Ahora bien, convendrá recordar que la LPC no es, por supuesto, la única ley que se ha descodificado. Según veremos, existen muchas otras. La descodificación de estas otras leyes nos interesa pues algunas de ellas disciplinan ámbitos en los que se presentan relaciones de consumo masivamente. Nuestra opinión es que la existencia de este tipo de leyes puede presentar dos amenazas a la descodificación material lograda a través de la LPC. Para comprender estas amenazas resulta necesario advertir que la convivencia de estas leyes especiales con la LPC puede organizarse de dos maneras diversas.

La primera de ellas es que se considere a la LPC - y a estas leyescomo especiales, y que se asuma que la ley general de referencia inmediata de todas ellas es el Código Civil. De esta manera, en todo aquello que no regula la ley especial se aplica el Código Civil. Al concebir de esta manera la primera forma de convivencia de las leyes que disciplinan ámbitos en que se presentan relaciones de consumo y la LPC, aparece con claridad la primera amenaza. En efecto, si las leyes especiales no disciplinan las cuestiones relativas a la relación entre las partes (proveedor/consumidor) y el derecho común de referencia inmediata es el Código Civil, entonces esa relación se administrará teniendo como telón de fondo la idea de igualdad formal que la LPC procuró superar.

9 Sobre este tema, como lo ha indicado uno de nosotros, dos posibles soluciones a las asimetrías que se producen con la contratación por adhesión parecieran ser la entrega de más información a los consumidores, o la incorporación de controles administrativos preventivos y de listados de cláusulas abusivas. Esta segunda opción es la más atractiva. Sobre esto véase de la MAZa GazMuri, Iñigo, ¿Por qué el Estado y no solamente el mercado?, en Revista Chilena de Derecho Privado I (2003), pp. I09-I48. 
La segunda manera de organizar la convivencia entre otras leyes especiales y la LPC consiste en asumir que la LPC constituye, respecto de estas leyes, la ley general de referencia inmediata. En este escenario aparece la segunda amenaza que consiste en que esas leyes especiales dispongan de disposiciones que devalúen la protección que les prodiga la LPC. ${ }^{10}$

Frente a estas dos amenazas, nuestra opinión es que, hasta ahora al menos, la descodificación material lograda a través de la LPC goza de buena salud. De una parte, debe considerársela como la ley general de referencia inmediata de las demás leyes especiales. Por otra parte, respecto de la segunda amenaza, el examen de las sentencias de tribunales superiores muestra un claro predominio de la LPC, lo cual evidencia que, por lo general, esas leyes no contienen disposiciones que prefieran a las de la LPC y, por lo mismo, no hay riesgo de devaluación de la tutela que prodiga a los consumidores.

\section{LA CONVIVENCIA DE LO GENERAL Y LO ESPECIAL}

Que una ley sea especial o general es que lo sea respecto de otra u otras leyes. Por lo mismo, según con qué se compare, podremos afirmar, sin riesgo de contradicción, que una ley es, simultáneamente, especial y general; especial respecto de algunas leyes y general respecto de otras. Esto es lo que, en nuestra opinión, sucede con la LPC.

Estimamos - $\mathrm{y}$ no nos parece seriamente discutible — que el Código Civil es general respecto de la LPC. Algo semejante podría decirse del $\mathrm{CPC}$ respecto de la LPC, un par de ejemplos servirán para mostrarlo. El Código Civil disciplina los contratos, pero, tratándose de los contratos que tienen lugar en una relación de consumo, concurre también la regulación de la LPC. Por otra parte, el CPC regula la fisonomía de los procedimientos, sin embargo, tratándose de aquellos procedimientos que surgen del incumplimiento de un contrato originado en el marco de una relación de consumo, concurre la LPC.

ro Sobre esta segunda amenaza, convendrá alguna precisión. Las leyes especiales diversas a la LPC se encuentran, por supuesto, descodificadas. Para que amenacen a la descodificación material efectuada por la LPC, ha de ser el caso que estas leyes especiales se encuentren descodificadas formalmente respecto de la tutela de la parte más débil. $\mathrm{O}$, para decirlo con mayor claridad, que no consideren las asimetrías entre las partes. Si esto sucede y se trata de ámbitos en los que se relacionan consumidores y proveedores $-\mathrm{y}$ resulta ser el caso que la ley especial contiene reglas incompatibles con las de la LPCentonces se verificará la amenaza. Así, por ejemplo, al comparar la normativa sectorial que regula las compensaciones por suspensión de servicio eléctrico del artículo i6 B de la Ley I8.4IO, se advierte que esta es significativamente menor a lo establecido en el artículo $25 \mathrm{~A}$ LPC, haciéndose presente la amenaza a la que se hace referencia. 
Si ahora nos preguntamos, ¿cuál es el criterio para determinar la especialidad de la LPC respecto del Código Civil o del CPC? La respuesta, como ha advertido uno de nosotros en otro trabajo, es la relación género-especie que puede establecerse entre estos códigos y la LPC. La LPC disciplina una porción de las relaciones que, en su ausencia, regularían estos códigos. Por otra parte, lo peculiar de esa porción es el tipo de relación de que se trata, una relación de consumo en los términos en que entiende esto la LPC.

Así sabemos que la LPC es especial respecto del Código Civil y del $\mathrm{CPC}$, y también qué es lo que la hace especial. Pero, como ya hemos sugerido, la LPC no es la única ley especial respecto del Código Civil que disciplina ámbitos en los que se desenvuelven relaciones de consumo. Como ya lo ha mostrado uno de nosotros, el criterio de género-especie no resulta útil para determinar si la LPC es general respecto de estas otras leyes. Sin embargo, nuestra opinión es que no cabe duda de que lo es. No es solo que así se desprenda de la Historia de la Ley I9.955 que introdujo el artículo 2 bis a la LPC, es que la lectura de dicho precepto enseña lo mismo.

Si se lee a contrario sensu la prevención con que comienza el artículo ("No obstante lo prescrito en el artículo anterior, las normas de esta ley no serán aplicables a las actividades de producción, fabricación, importación, construcción, distribución y comercialización de bienes o de prestación de servicios reguladas por leyes especiales, salvo...») resulta sencillo advertir que las normas de la LPC se aplican, aun existiendo leyes especiales, en las materias que las leyes especiales no prevean y, habría que agregar, que la LPC haya previsto.

Miradas las cosas de esta manera, lo dispuesto por el artículo 2 bis es lo mismo que dispone el artículo 2 del Código de Comercio ( $E n$ los casos que no estén especialmente resueltos por este Código, se aplicarán las disposiciones del Código Civil»). La diferencia es que, tratándose de la LPC, la disposición se encuentra en la ley general, no en la especial.

De esta manera, resulta que, si bien tanto la LPC como el Código Civil son leyes generales respecto de aquellas que el artículo 2 bis de la LPC denomina "leyes especiales», la LPC es la ley general de referencia inmediata. Es decir, frente a un vacío en la ley especial, el intérprete debiese acudir a la LPC y, únicamente, si no se encuentra una solución en ella, continuar hacia el Código Civil.

Lo anterior no obstante que se haya planteado la posibilidad de que el consumidor pueda optar por el régimen de la LPC o el del Código Civil, en aquellos casos en que la tutela de la Ley del Consumidor no sea la 
más beneficiosa. ${ }^{\text {II }}$ En dichas circunstancias, la doctrina que ha estudiado el tema favorece la opción del consumidor de elegir, a pesar de la especialidad del derecho del consumidor sobre el derecho civil, siempre que el estatuto de la LPC no sea el más favorable. ${ }^{12}$ Como se ve, entonces, la primera amenaza a la descodificación material es conjurada por la propia LPC a través del diseño del artículo 2 bis, que la establece como ley general de referencia inmediata.

Antes de abandonar esta sección, conviene prestar atención a un aspecto que revela el examen del artículo 2 bis. La generalidad de la LPC no se limita a cuestiones sustantivas, sino que comprende también cuestiones procedimentales. El punto es interesante, pues alguna doctrina procesal ha señalado que, tratándose de los códigos de procedimiento civil del siglo XIX, también se asume una noción de igualdad formal respecto de los litigantes. ${ }^{13}$ Esa noción de igualdad, sin duda, se ve alterada por otra más atenta a las condiciones materiales a partir de la Ley 19.955, que introduce las acciones de interés colectivo y difuso, ${ }^{14} \mathrm{y}$ la Ley 2I.08I, que introduce modificaciones, tanto al régimen de esas acciones como a las de interés individual, en beneficio de los consumidores.

\section{Leyes especiales y la Ley de Protección de los Derechos DE los Consumidores: La MIRAda DE los tribunales}

La segunda amenaza a la descodificación material plasmada a través de la LPC proviene, una vez más, de la existencia de leyes especiales, pero esta vez no se trata de determinar cuál es la regla general —ya se sabe que es la LPC—, sino de determinar si la concurrencia de la ley especial excluye la aplicación de la ley general. Si la excluye es porque contiene normas que resultan incompatibles con lo dispuesto en la LPC. Dicha exclusión

II Sobre este tema, véase Verónica López, Patricia, La tutela precontractual en la Ley 19.496: su configuración, alcance y eventual convergencia con aquella propia de la contratación civil, en Revista Chilena de Derecho, 2 (2019) 46, p. 418.

${ }^{12}$ Ibid.

${ }^{13}$ Ver Bordali-Salamanca, Andrés, La carga de la prueba en el proceso civil: una evolución desde la igualdad formal de las partes hacia una igualdad material de las mismas, en Revista de Derecho 23 (2016), pp. I73-198.

${ }^{14}$ En dichas acciones, lo que se tutela ya no es la posición de un consumidor, sino la de un grupo determinado o determinable mucho más amplio, y el problema supone (las acciones de interés supraindividual) la necesidad de establecer un interés heterogéneo que pueda ser tutelado de forma común. Sobre este tema véase Aguirrezábal Grünstein, Maite, Comentario artículo 5o, en De la Maza, Iñigo y Pizarro, Carlos (directores), La protección de los derechos de los consumidores (Santiago, 2013, Legal Publishing) p. 972. 
podría ser tanto respecto de cuestiones sustantivas como procedimentales según lo dispuesto por el artículo 2 bis.

Sostenemos que, por regla general, la existencia de leyes especiales que disciplinen ámbitos en que se desarrollan relaciones de consumo no evita la aplicación de la LPC. Si eso es correcto, ha de ser el caso que las leyes especiales no disponen de reglas que recaigan sobre aquellas cuestiones que disciplina la LPC y, si es así, la concurrencia de esas leyes especiales no devalúa la tutela que la LPC prodiga a los consumidores.

A diferencia del carácter general de la LPC, esta tesis no puede acreditarse únicamente con cargo a la historia de la ley o a su contenido, sino que, en cambio, resulta indispensable acometer una tarea más extensa, consistente en examinar cómo han resuelto los tribunales los casos de concurrencia. Para cumplir dicho objetivo, realizamos una extensa búsqueda de sentencias de los tribunales superiores en las que se discutiera la posibilidad de aplicar la LPC al caso concreto, al existir una ley o norma que regula el mismo supuesto de hecho, o el mismo mercado al que se pretende aplicar la Ley del Consumidor, resolviéndose el conflicto en consideración al artículo 2 bis. ${ }^{15}$ Tras la recopilación, revisión y clasificación de los fallos encontrados, llegamos a una muestra final de iI8 sentencias, de las cuales 2I fueron dictadas por la Corte Suprema, y el resto por diversas Cortes de Apelaciones.

Como se advierte en la figura I, de esos iI8 fallos, un primer grupo, compuesto de 27 sentencias, corresponden a acciones presentadas en tutela del interés supraindividual, en su mayoría a propósito de instituciones educacionales, ${ }^{16}$ en los que se discute acerca del procedimiento a través del

is La selección de las sentencias se realizó mediante una búsqueda por palabra clave («I9.496», «2 bis», "consumidor») y con criterio temporal (desde enero de 2004 hasta abril de 2020) en los portales de jurisprudencia de Legal Publishing y Vlex. Los resultados fueron filtrados para incluir solo las sentencias de Cortes de Apelaciones y de Corte Suprema, las que fueron incluidas en un listado.

Luego, se revisaron las sentencias seleccionadas, las que fueron fichadas con el objetivo de mantener únicamente aquellas en que el tribunal advirtiera en los considerandos de la sentencia el conflicto de normas y la aplicación del artículo 2 bis. Por lo mismo, se descartaron las sentencias en las que el tribunal no aportó consideraciones de relevancia a propósito de la posibilidad de aplicar la normativa de protección al consumidor en un caso específico (por ejemplo, si ignoraba completamente la discusión, y resolvía el conflicto por temas de prescripción).

Tras dicha operación, el resultado fue un total de ir8 sentencias, que fueron clasificadas por mercado (financiero, aerolíneas, etcétera), por el tipo de especialidad que se discute (especialidad de materia o de procedimiento), y según si se determinó la aplicación de la LPC, o bien, de la norma o ley que regula el supuesto que se discute.

${ }^{16}$ De esta manera, de las 27 sentencias Io se enmarcan en el mercado educacional, 4 


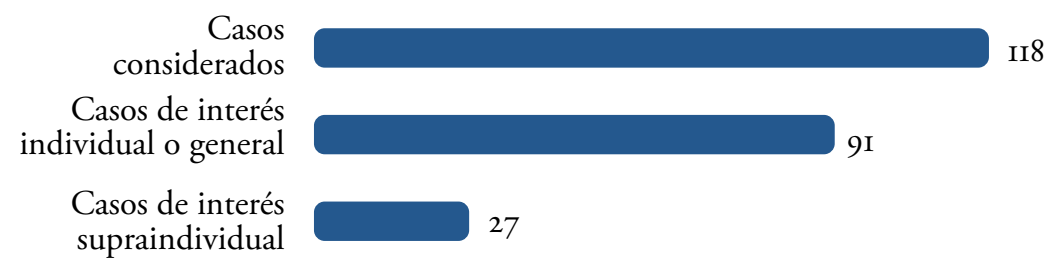

Figura I. Casos considerados según interés afectado.

cual debe desarrollarse el juicio y, en particular si es posible considerar que la acción intentada corresponde a un consumidor en particular, o bien, al colectivo.

El segundo grupo de casos, que es el que resulta de mayor interés para esta investigación, ${ }^{17}$ se refiere a aquellos procedimientos individuales iniciados por un consumidor (o por el Sernac en representación del interés general). Este segundo grupo de casos comprende las 9I sentencias restantes. De ellas, en 72 se resolvió que se aplicaba la LPC. Es decir, en el $79 \%$ de las sentencias revisadas se resolvió que, ya sea por cuestiones relativas a la materia sustantiva o al procedimiento para solicitar la indemnización de perjuicios, la LPC se aplicaba por sobre la normativa específica de la materia.

Dentro de estos 9I casos de interés individual, el estudio de las sentencias muestra que los ámbitos con mayor cantidad de fallos son (de mayor a menor): a) financiero (22 casos o $24 \%$ ), b) aerolíneas (I2 casos o I3\%), c) correos (Io casos o Io,9\%), d) servicios básicos (aguas y electricidad, 9 casos o $9,8 \%$ ), e) seguros (8 casos o $8,7 \%), f$ ) autopistas ( 5 casos o $5,4 \%$ ), g) telecomunicaciones ( 5 casos o $5,4 \%$ ), h) construcción ( 5 casos o $5,4 \%$ ). Los casos restantes se dividen en sentencias sobre: alimentos (3), arrendamiento (I), educación (2), farmacias (I), retail (3), servicios de recreación (3), transporte (I) y otros (I).

La figura 2 muestra la cantidad de casos totales considerados por mercado, dando cuenta que la compatibilidad de la LPC con leyes especiales se discute, principalmente, en el mercado financiero, aeronáutico y de

en el financiero, 3 en servicios básicos, 2 en retail, 2 en servicios de recreación, y el resto se reparte en aerolíneas, construcción, farmacias y transporte.

${ }^{17} \mathrm{La}$ razón de esto se debe a que en los casos en los que se discute la afectación al interés colectivo o difuso, la discusión sobre la posibilidad de aplicar la LPC en atención al artículo 2 bis se enmarca en el estudio de la competencia del Juzgado Civil, y no en si la materia o el procedimiento que se discute se encuentran regulados por la ley específica. Sin embargo, algunas sentencias aportan consideraciones de importancia que se mostrarán. 


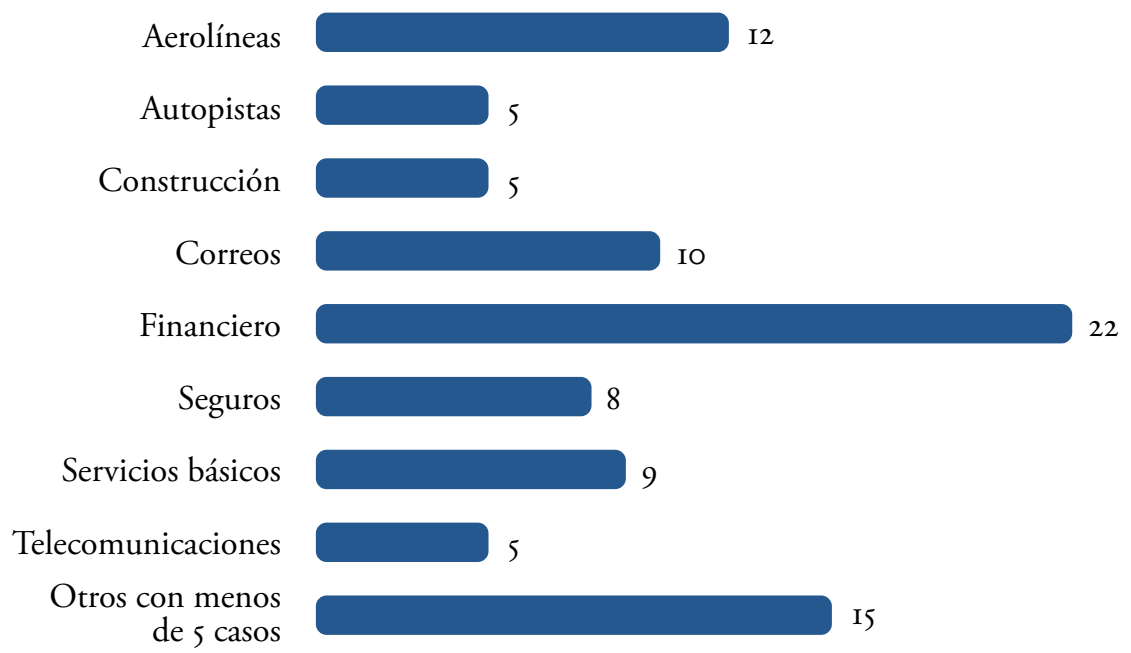

Figura 2. Mercados de los casos de interés individual o general considerados.

correos. Ahora, esto no necesariamente significa que sean los mercados con el mayor porcentaje de aplicación de la LPC por sobre la normativa especial, cuestión que se revisa a continuación.

\section{a) El predominio de la LPC}

La figura 3 muestra que del hecho que se discuta la aplicación de la LPC en un caso, no necesariamente determina su aplicación. Sin embargo, en la gran mayoría de los casos pareciera aplicarse; los principales mercados en que se favorece la Ley del Consumidor (en atención a cantidad de casos totales en comparación a aquellos en que se aplica la LPC) son el financiero, el aeronáutico y el de servicios básicos.

Tratándose del mercado financiero (en el cual se incluyen principalmente bancos, pero también otras instituciones financieras, como cajas de compensación) se analizaron 22 casos de interés individual o general. De ellos, en I9 (el 86\%) los tribunales decidieron que la existencia de una ley especial no desplazaba la LPC. De esos i9 fallos, I7 lo hace por cuestiones relativas a la materia, mientras que solo 2 por asuntos relativos al procedimiento (incluyéndose el caso de interés supraindividual).

Así, por ejemplo, por lo que toca a las cuestiones relativas a materia, y frente a alegatos de incompetencia de los Juzgados de Policía Local, se ha dicho que la normativa a que están sujetos los Bancos respecto de la Superintendencia de Bancos e Instituciones Financieras (hoy llamada Comisión para el Mercado Financiero) resulta perfectamente compatible con 
la $\mathrm{LPC},{ }^{18}$ o bien que, al tratarse de un organismo administrativo la SBIF carece de facultades para resolver la infracción denunciada. ${ }^{19}$

También se ha indicado que, si bien la Ley General de Bancos le otorga competencia para la fiscalización de las instituciones bancarias, dicha norma nada señala a propósito de las relaciones entre el banco y un consumidor cuando se denuncia una negligente prestación de servicio. ${ }^{20} \mathrm{~A}$ la misma conclusión se ha llegado respecto a otras leyes cuya concurrencia se ha discutido en el mercado financiero. ${ }^{2 \mathrm{I}}$

En lo que concierne a cuestiones procedimentales se ha resuelto que, no habiendo un procedimiento indemnizatorio en la Ley General de Bancos para los daños que se originen con ocasión de los actos que se fiscalizan, estas acciones deben ser conocidas por los Juzgados de Policía Local de conformidad a las disposiciones de la Ley 19.496. ${ }^{22}$ Lo mismo se ha resuelto a propósito de la Ley de Cuentas Corrientes Bancarias y Cheques. ${ }^{23}$

Por otra parte, cabe mencionar que, tratándose de una acción de interés colectivo, la Corte de Apelaciones de Santiago, conociendo de un caso en que se alegó que el banco habría establecido condiciones no pactadas, se pronunció a favor de la compatibilidad entre las disposiciones de la LPC con la normativa bancaria, en cuanto la primera no busca fiscalizar las operaciones o negocios de dichas instituciones, sino el cumplimiento de las obligaciones del proveedor. ${ }^{24}$ En el mismo sentido, en otro caso, se

${ }^{18}$ Corte de Apelaciones de Coyhaique, 28 de febrero de 2008, rol 2-2008. En el mismo sentido, la Corte de Apelaciones de Valdivia indicó que, si la normativa bancaria fuera excluyente, las disposiciones financieras introducidas por la Ley 20.555 no tendrían ningún sentido. Corte de Apelaciones de Valdivia, I9 de noviembre de 20I4, rol I95-20I4.

19 Corte de Apelaciones de Santiago, 23 de marzo de 2005, rol 6175-2003.

${ }^{20}$ En efecto, en dicha oportunidad el tribunal sostuvo: "Si bien la Ley General de Bancos le otorga a la Superintendencia de Bancos e Instituciones Financieras la facultad de fiscalización de las empresas bancarias, según lo dispone el articulo 2 del Decreto con Fuerza de Ley 3 , lo cierto es que no existe reglamentación en ella referida a las operaciones de crédito como las indicadas en la querella de autos, ni a las relaciones entre el banco y un consumidor cuando se denuncia una negligente prestación de servicios, de manera que es plenamente aplicable la Ley sobre $P$. de los Derechos de los Consumidores, conforme a lo dispuesto en la letra a) del articulo 2 bis de la mencionada ley».

${ }^{21}$ Así, refiriéndose a la alegación relativa a que los asuntos regulados por la Ley sobre Cuentas Corrientes Bancarias y Cheques (DFL 707) son de conocimiento de los Juzgados Civiles, la Corte de Apelaciones de Iquique indicó que, tratándose de infracciones sobre la falta de información veraz y oportuna, la competencia es de los Juzgados de Policía Local. Véase Corte de Apelaciones de Iquique, rol 39-2015, 28 de septiembre de 2015.

${ }_{22}$ Corte de Apelaciones de Coyhaique, 20 de noviembre del 2006, rol 22-2006.

${ }^{23}$ Corte de Apelaciones de Valdivia, I3 de septiembre de 2013, rol 165-20I3.

${ }^{24}$ Corte de Apelaciones de Santiago, I de julio de 2005, rol 5IO4-2005. 


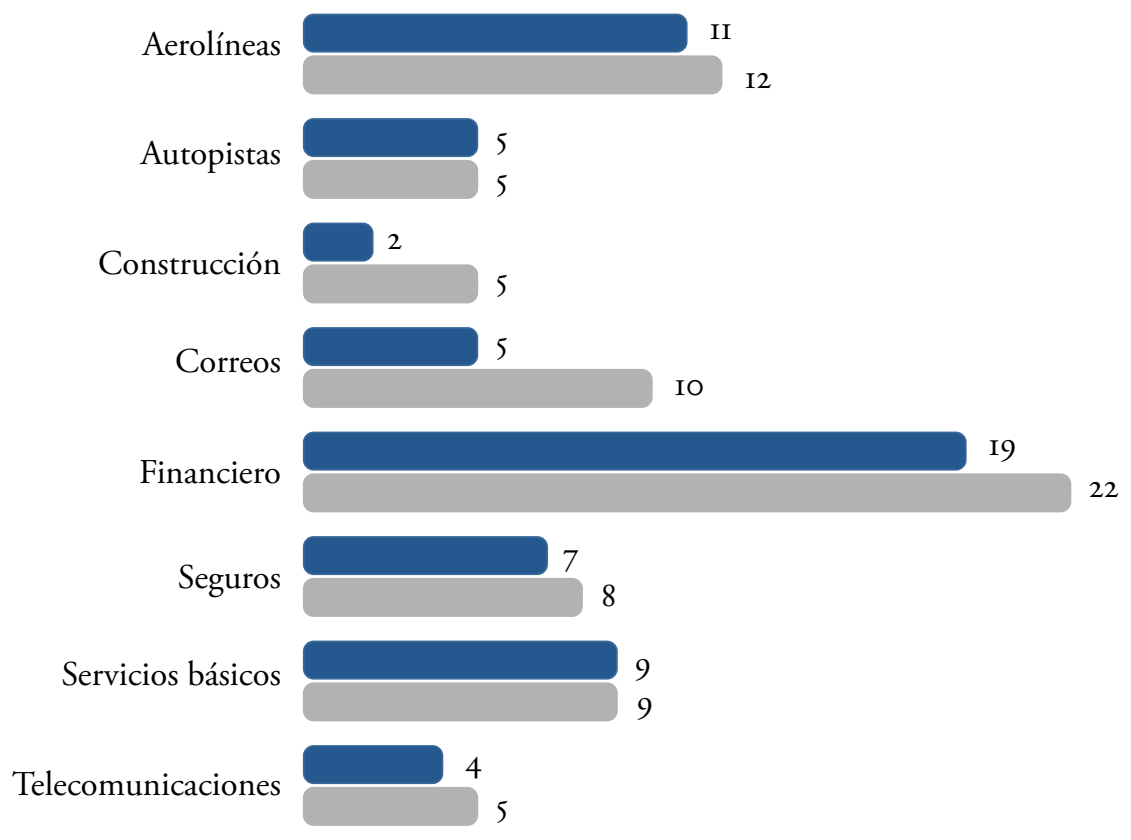

Figura 3. Cantidad de casos en que se aplicó la LPC/total de casos de interés individual o general revisados.

determinó que, aun si se trata de un servicio regulado en una ley especial, debe aplicarse el procedimiento de tutela de interés colectivo contemplado en la LPC si se ve afectado el interés colectivo o difuso de los consumidores. ${ }^{25}$ Asimismo, la Corte Suprema ha resuelto que, aun cuando el pleito diga relación con cuestiones reguladas en leyes especiales (en este caso, datos personales), resulta procedente aplicar las disposiciones relativas al procedimiento de tutela de interés supraindividual de la LPC cuando se vean vulnerados intereses colectivos. ${ }^{26}$

Sobre el ámbito aeronáutico, nuestra investigación arrojó I3 sentencias, I2 iniciadas a través de acciones de interés individual (en II se determinó que resultaba aplicable la LPC). En la sentencia restante se discutió la competencia del tribunal tratándose de asuntos de interés supraindividual. ${ }^{27}$

En lo que toca a cuestiones relativas a la especialidad material en el mercado aeronáutico, en una sentencia dictada por la Corte de Apelacio-

${ }^{25}$ Corte Suprema, 28 de octubre de 20I3, rol 3978-20I3.

${ }^{26}$ Corte Suprema, II de octubre de 2016, rol 4903-20I5. En un sentido semejante, véase Corte de Apelaciones de La Serena, 3I de diciembre de 20Io, rol 86-20Io.

${ }^{27}$ Corte de Apelaciones de Concepción, I7 de junio de 2009, rol 352-2008. 
nes de Valparaíso se determinó que la normativa del Código Aeronáutico no constituye una de las excepciones referidas en el artículo 2 bis de la LPDC, por cuanto no regula el tipo de transacción que dio origen a la denuncia, agregando que, en realidad, la competencia de la Dirección General Aeronáutica, valga la redundancia, es para temas de aeronáutica. ${ }^{28}$ De forma similar, la Corte Suprema ha determinado que, si bien el Código Aeronáutico contiene disposiciones especiales respecto al contrato de transporte aéreo, el retardo o la denegación del servicio en la forma convenida no importa una infracción a dicha ley, sino al contrato, debiendo ser conocida por los tribunales de justicia y no por la autoridad administrativa, cuyas funciones se limitan a la protección de la seguridad aérea. ${ }^{29}$

En otro caso, la Corte de Apelaciones de Antofagasta consideró que la entrega tardía de equipaje no queda comprendida en el supuesto del artículo I48 del Código Aeronáutico, por lo que no se trataría de una materia regulada en la norma especial, siendo competente el Juzgado de Policía Local y no la Dirección General Aeronáutica. ${ }^{30}$

En un caso más reciente, la Corte de Apelaciones de Valparaíso estableció que el Código Aeronáutico regula todo lo relativo a la prestación de servicio de transporte aéreo, contratos de transporte aéreo y las responsabilidades que estas originen, siempre que el servicio en cuestión se efectúe en el territorio nacional, cuestión que no correspondía con el caso en particular que se resolvió, en el cual el consumidor contrató con un intermediario (esta situación que no estaría prevista en el Código Aeronáutico), determinando que fuera aplicable la LPC. ${ }^{31}$ Finalmente, la Corte de Apelaciones de Valdivia ha advertido la ambigüedad del texto del artículo I84 del Código Aeronáutico, determinando que su adecuada comprensión supone entender que la competencia de la Dirección General Aeronáutica debe ser limitada a las infracciones sobre aeronáutica. ${ }^{32}$

Pasando al segundo grupo de casos aeronáuticos, en que lo discutido dice relación con la falta de un procedimiento, convendrá comenzar con una sentencia dictada por la Corte de Apelaciones de Santiago en la cual se indicó que, aun cuando el Código Aeronáutico es un cuerpo normativo especial que contiene normas sobre el contrato de transporte aéreo y la responsabilidad del transportador, dicho cuerpo normativo no contempla normas especiales de procedimiento para hacer efectivas las indemnizacio-

\footnotetext{
${ }^{28}$ Corte de Apelaciones de Valparaíso, 28 de diciembre de 2004, rol 56I-2004.

29 Corte Suprema, 2I de julio de 2008, rol 3023-2008.

${ }^{30}$ Corte de Apelaciones de Antofagasta, Io de junio de 20II, rol 63-20II.

${ }^{31}$ Corte de Apelaciones de Valparaíso, I9 de julio de 20I2, rol I88-20I2.

${ }_{32}$ Corte de Apelaciones de Valdivia, 7 de julio de 20I4, rol 5I-2OI4.
} 
nes, por lo que es aplicable el procedimiento contemplado en la LPC, sin perjuicio de que el Juzgado de Policía Local deba resolver conforme a las normas sustantivas del Código Aeronáutico (cuestión a la que volveremos al tratar la cuestión de la concurrencia excluyente). ${ }^{33}$ De forma similar se pronunció una sentencia posterior dictada por la Corte de Apelaciones de Copiapó, estimando que, al no contemplar la normativa especial en cuestión un procedimiento de carácter indemnizatorio, se debe aplicar la norma contenida en el artículo 2 bis letra c), pudiendo el consumidor recurrir conforme al procedimiento de la LPC ante el Juzgados de Policía Local correspondiente. ${ }^{34}$

En el mercado de suministro de servicios básicos concesionados (agua potable y electricidad) encontramos 9 fallos; en todos se ha estimado que procede la aplicación de la LPC. La lectura de estos fallos enseña que lo determinante para la procedencia de la LPC no es que la materia se encuentre regulada en una normativa especial, sino si esta contiene una regulación especial, tanto en términos sustantivos como procedimentales, de los aspectos propios de la relación de consumo (permitiendo asegurar el resguardo del consumidor y la efectiva posibilidad de que haga valer sus derechos). ${ }^{35}$

${ }_{33}$ Corte de Apelaciones de Santiago, 5 de noviembre de 2007, rol 4205-2007.

34 Corte de Apelaciones de Copiapó, 23 de marzo de 20Io, rol 3-20Io.

${ }_{35}$ Así, por ejemplo, tratándose de los servicios de suministro de agua potable, la Corte de Apelaciones de Copiapó rechazó la alegación de incompetencia presentada por el proveedor, en cuanto la normativa especial que se alegaba no contiene un procedimiento indemnizatorio (Corte de Apelaciones de Copiapó, 7 de julio de 20II, rol 27-20II). En otro caso, la Corte Suprema determinó la procedencia de la aplicación la LPC en cuanto la normativa sanitaria no contiene una regulación sobre procedimientos colectivos (Corte Suprema, 23 de julio de 2014, rol 9025-2013).

En lo que toca a los servicios eléctricos, la Corte de Apelaciones de Valparaíso ha señalado que la regulación especial sobre el suministro eléctrico coexiste de forma no excluyente con la normativa de protección al consumidor, quedando sujeta la empresa a esta última atendida su naturaleza de proveedor. Corte de Apelaciones de Valparaíso, 22 de septiembre de 2004, rol II557-2003. En un sentido similar, la Corte de Apelaciones de Santiago ha resuelto (de forma similar a lo que sucede con la Dirección General Aeronáutica, según se mostró) que la Superintendencia de Electricidad y Combustibles resuelve cuestiones técnicas, pero no jurisdiccionales, por lo que se aplican las reglas de competencia de la LPC para conocer las infracciones que vulneran derechos de los consumidores. En fin, la Corte de Apelaciones de San Miguel ha indicado que la acción ante los Juzgados de Policía Local no obsta a la que pueda interponerse ante autoridades administrativas de conformidad a la Ley i8.4Io y su Reglamento. Corte de Apelaciones de San Miguel, I3 de julio de 2006, rol 1757-2004. En el mismo sentido, Corte de Apelaciones de Santiago, 7 de abril de 2006, rol 4792-2005. 
En el ámbito de los seguros nuestra investigación arrojó 8 sentencias, y en 7 de ellas se resolvió que la LPC resulta aplicable, a pesar de la regulación contenida sobre el contrato de seguro en el Código de Comercio, el DFL 251, y el DS 863 de 1989. En los procedimientos en que se discutió acerca de la especialidad por cuestiones sustantivas por infracción de los artículos i2 y 23 LPC, se estableció que ninguna de las referidas leyes (Código de Comercio, el DFL 251 y el DS 863 de 1989) contemplaba normas sobre la infracción específica alegada, y era procedente aplicar las de la Ley 19.496. ${ }^{36}$ Asimismo, se indicó que la LPC establece requisitos más exhaustivos que el Código de Comercio, sobre la información que debe entregarse, y lo que procede es complementar la normativa específica con la Ley del Consumidor. ${ }^{37}$

En lo que respecta a cuestiones procedimentales, una sentencia de la Corte de Apelaciones de Antofagasta estableció que, atendida la falta de regulación de un procedimiento especial en las normas específicas alegadas por la empresa demandada, correspondía la aplicación de la LPC. ${ }^{8}$ Por su parte, una sentencia de la Corte de Apelaciones de Coyhaique sostuvo que, en realidad, la normativa de protección al consumidor sería específica y por ello compatible con las demás. ${ }^{39}$

Luego, en el caso de las autopistas concesionadas, la existencia de una ley especial de acuerdo con el 2 bis $^{40}$ se ha discutido en cinco fallos. En todos ellos se ha establecido que la LPC es aplicable, a falta de un procedimiento indemnizatorio en el Decreto Supremo 900 de 1996 (Ley de Concesiones de Obras Públicas). ${ }^{4 \mathrm{I}}$

${ }^{36}$ Corte de Apelaciones de Concepción, 6 de diciembre de 20I2, rol 268-20I2. En el mismo sentido, Corte de Apelaciones de Concepción, 9 de febrero de 2015, rol 235-2015.

${ }_{37}$ Corte de Apelaciones de Santiago, 8 de julio de 20I6, rol 594-20I6.

${ }^{38}$ Corte de Apelaciones de Antofagasta, I9 de marzo de 20I2, rol 235-20I4; Corte de Apelaciones de Santiago, 16 de abril de 2013, rol IO28-20I2; Corte de Apelaciones de Santiago, 30 de junio de 20I4, rol 265-20I4.

39 Corte de Apelaciones de Coyhaique, 23 de abril de 2015, rol 7-20I5.

$4^{\circ}$ Convendrá advertir que los casos en los que se discute la aplicación de la Ley del Consumidor por existencia de una normativa especial, coexisten con otro grupo de fallos que no nos interesan para este trabajo (y que no fueron incluidos en la estadística presentada anteriormente): aquellos en los cuales lo que se discute es si la suma que el consumidor desembolsa para utilizar la autopista puede ser considerada como un precio, justificando la existencia de una relación contractual con la concesionaria, o bien, si debe descartarse esa posibilidad, negando que pueda accionar ante los juzgados de policía local al no existir un contrato por adhesión. Por ejemplo, Corte de Apelaciones de Valdivia, 3 de septiembre de 20I3, rol IIO-20I3; Corte de Apelaciones de Valparaíso, 24 de agosto de 20I5, rol 229-20I5; Corte de Apelaciones de Talca, 6 de noviembre de 2015, rol 272-2015; Corte de Apelaciones de Valdivia, I9 de noviembre de 20I5, rol 179-20I5.

${ }^{41}$ Así, por ejemplo, en una sentencia de la Corte de Apelaciones de La Serena se falló 
Sobre los servicios de telecomunicaciones - a propósito de los cuales se reitera que la falta de un procedimiento indemnizatorio especial en la Ley I8.I68 y su reglamento, hace procedente las disposiciones de la Ley del Consumidor $-{ }^{42}$ también se ha establecido la procedencia de la acción en contra de empresas de telecomunicaciones sin mayor detención sobre la existencia de una normativa especial, tras determinar la calidad de proveedor del demandado, ${ }^{43} \mathrm{o}$ de consumidor del demandante. ${ }^{44}$

Para recapitular, si bien lo que se ha presentado hasta ahora constituye una cantidad importante de información, la conclusión es sencilla: en estos mercados, que son la mayor parte de los encontrados para la elaboración de la investigación previa a este trabajo, los tribunales han optado por favorecer la aplicación de la LPC, ya sea por cuestiones sustantivas o procedimentales. Y, en términos generales, la conclusión que pareciera desprenderse consiste en que no es suficiente que la normativa específica regule un mercado, sino que debe prever la posibilidad de que se produzca una relación de consumo, a riesgo de que aplique la Ley 19.496 en su defecto.

lo siguiente: «si bien el Decreto Supremo 9oo, publicado el I8 de diciembre de 1996, que fija el texto refundido del DFL I64, conocido como Ley de Concesiones de Obras Públicas, constituye un cuerpo normativo especial que establece un conjunto de reglas destinadas a regular la ejecución, reparación, conservación o explotación de obras públicas fiscales, las licitaciones y concesiones que deban otorgarse, ya se trate de la explotación de las obras o servicios, del uso y goce sobre bienes nacionales de uso público o fiscales, destinados a desarrollar las áreas de servicio que se convengan, de la provisión de equipamiento o la prestación de servicios asociados, no obstante, dicho texto legal no contempla mecanismos especiales de procedimiento para hacer efectivas las normas de responsabilidad en él contenidas ni para obtener las indemnizaciones de los daños causados al usuario con motivo u ocasión del incumplimiento de los deberes $u$ obligaciones que se imponen al concesionario, por lo que, efectivamente, resulta procedente la aplicación del procedimiento contemplado en la Ley 19.496, para perseguir la responsabilidad de aquel, sin perjuicio que el Juez de Policía Local deba resolver el asunto conforme a las normas sustantivas o de fondo previstas en el citado Decreto Supremo». Corte de Apelaciones de La Serena, 3 de agosto de 20I2, rol I79-20Ir. De forma similar, véase Corte de Apelaciones de Valparaíso, 2 de octubre de 20I4, rol 424-20I4; Corte de Apelaciones de Valparaíso, 4 de mayo de 20I5, rol I04-20I5; Corte de Apelaciones de San Miguel, I7 de noviembre de 2017, rol 970-2017.

${ }^{42}$ Corte de Apelaciones de Puerto Montt, I6 de agosto de 2007, rol 252-2007. De manera similar, véase Corte de Apelaciones de San Miguel, 4 de agosto de 2008, rol IO42008.

${ }^{43}$ Corte de Apelaciones de Chillán, 4 de julio de 20II, rol 34-20II.

${ }_{44}$ Corte de Apelaciones de Antofagasta, 29 de diciembre de 2016, rol 157-20I6. 


\section{LA APLICACIÓN DE LAS LEYES ESPECIALES}

Que la LPC se aplique predominantemente cuando concurre con una ley especial no significa que las leyes especiales nunca prefieran a la LPC. En nuestra investigación hemos encontrado dos tipos de excepciones en la que se aplican las leyes especiales.

Denominamos a las primeras excepciones impropias porque, en verdad, se explican por una confusión de los tribunales entre la existencia de una ley especial y la aplicación del principio de especialidad normativa. ${ }^{45} \mathrm{El}$ segundo grupo corresponde a excepciones propiamente tales, pues se trata de casos en los que la ley especial diverge sustantiva o procedimentalmente de la LPC y, por lo mismo, la prefiere.

Un ejemplo de excepción impropia se encuentra en el ámbito de los servicios financieros (en el cual se aplicó la LPC en is de 22 casos). Puede considerarse una sentencia de la Corte de Apelaciones de Santiago, en la cual, tras indicar que la Ley General de Bancos otorga a la SBIF la fiscalización de las empresas cuyo giro consista en la emisión u operación de tarjetas de crédito o de cualquier otro sistema similar, se indica que «al estar regulada la prestación del servicio en una ley especial, la Ley General de Bancos, de acuerdo a lo dispuesto en el artículo 2 bis y 50 A inciso tercero de la Ley 19.496, son competentes para conocer de la acción los tribunales ordinarios de justicia, tal como dispone la parte final del artículo so $\mathrm{A}$, recién citado por no estar mencionada en los casos de excepción referidos en las normas citadas en el considerando segundo de este fallo [el artículo 2 bis]》. ${ }^{46}$

Encontramos un segundo ejemplo en la sentencia de la Corte de Apelaciones de Santiago del 16 de agosto de 20I3, en que se estimó que las infracciones cometidas por las cajas de compensación deben ser conocidas por la superintendencia respectiva, destacándose el hecho de que el Sernac solo buscó la responsabilidad infraccional y no la civil. ${ }^{47}$

45 Sobre esta diferencia, véase de la Maza Gazmuri, Ińigo, cit. (n. 9).

${ }_{46}$ Corte de Apelaciones de Santiago, 27 de agosto de 2013, rol 1327-20I2.

47 "Que, el que la conducta infraccional en estos casos quede entregada a un organismo administrativo — la Superintendencia de Seguridad Social - en lugar de un órgano jurisdiccional —un Juzgado de Policía Local-como pretende el Sernac, es de toda lógica, desde que se trata de materias de orden técnico que involucran prestaciones de seguridad social, esto es, los créditos de consumo a personas de tercera edad afiliadas en virtud del articulo I6 de la Ley I9.539 a las Cajas de Compensación de Asignación Familiar, respecto de los cuales el órgano administrativo está revestido de facultades legales especiales para fiscalizar las actuaciones que corresponda. En esta linea, nada obsta a que sea el propio Sernac quien movido por el interés general que invoca, ponga los antecedentes respectivos en manos de la autoridad administrativa con facultad legal para sancionar. 
El tercer ejemplo corresponde a una sentencia de la Corte de Apelaciones de Talca: el tribunal se limitó a indicar, a propósito de la aplicación de la LPC, que "el artículo 2 bis de la Ley 19.496 excluye de la aplicación de esta ley, a las empresas de servicios reguladas por leyes especiales, lo que ocurre en la especie». ${ }^{48}$

El problema que presentan los casos de excepción impropia está dado por una falta de argumentos en la sentencia que no permite entender si la exclusión de la LPC se debió a la simple existencia de una ley especial sobre la materia o, en cambio, existió otra razón que justificara la exclusión de la LPC. La razón tendría que ser que el problema en particular ha sido tratado por dicha normativa, permitiendo excluir la aplicación de la Ley del Consumidor.

Tratándose de excepciones propiamente tales, encontramos dos ámbitos. El primero corresponde al de la construcción. En este, por lo general, se resuelve que la LPC no se aplica. ${ }^{49}$ Así, por ejemplo, puede verse una sentencia de la Corte de Apelaciones de Santiago, en la que se indicó que, tratándose de los defectos en la construcción: "5o. Que la acción para demandar por daños que tienen por causa supuestos defectos en la calidad de la construcción, es de competencia de los tribunales civiles y se somete a las reglas del procedimiento sumario, por expresa disposición del artículo Io de la Ley General de Urbanismo y Construcción.

"60. Que la Ley 19.496, en materia de la construcción hace prevalecer las leyes especiales, limitando su aplicación a situaciones no reguladas por ella. Por consiguiente, estando consagrada la obligación de garantía del primer vendedor, esto es, la responsabilidad de la empresa vendedora, y de los constructores $y$ proyectistas por las fallas o defectos de construcción que hayan dado origen a los daños y la acción para perseguir el resarcimiento de los tales perjuicios en la ley General de Urbanismo y Construcción, no puede sino concluirse que el Juzgado de Policía Local carece de competencia, en razón de la materia, para pronunciarse sobre el asunto propuesto.

"Que, en lo referido a eventuales indemnizaciones de perjuicios que pudiesen reclamar las personas de la tercera edad que, siendo afiliadas a una Caja de Compensación de Asignación Familiar, quisieran reclamar en sede jurisdiccional, ello no se vincula con el caso sub-lite, pues el Sernac solo ha accionado en lo infraccional", Corte de Apelaciones de Santiago, I6 de agosto de 2013, rol I678-20I2.

${ }^{48}$ Corte de Apelaciones de Talca, 13 de julio de 20II, rol 4I3-20II. En el resto del fallo el tribunal justifica la incompetencia del juzgado de policía local, puesto que esta corresponde a un árbitro y luego a la justicia civil.

49 En efecto, esta solo se aplica en 2 de los 5 casos encontrados. Corte de Apelaciones de Antofagasta, 22 de julio de 20I5, rol I05-20I5 y Corte de Apelaciones de Santiago, I de julio de 20I6, rol 480-2016. 
"70. Que, en efecto, la Ley General de Urbanismo y Construcción consagra normas legales que posibilitan al consumidor - comprador en este caso-el ejercicio de acciones destinadas a perseguir la responsabilidad del vendedor y demás participantes en la ejecución de la obra, a objeto de obtener el resarcimiento de los perjuicios causados por hechos derivados de defectos en la construcción». 50

En el mismo sentido puede consultarse una sentencia dictada por la Corte de Apelaciones de Valparaíso. ${ }^{\text {.1 }}$ Habrá que notar que la LPC únicamente se excluye en estos casos respecto de aquello que ha sido considerado por la LGUC, no existiendo inconvenientes para que la primera se aplique respecto de materias no consideras por la segunda; por ejemplo, como ocurre con la infracción de deberes de información como complemento de la deficiente regulación de la integración publicitaria del artículo I8 LGUC.

El segundo ámbito corresponde al de los servicios de correos: es posible indicar que en la mayoría de los casos se excluye la aplicación de la Ley del Consumidor y, curiosamente, los casos encontrados son todos de la misma Corte de Apelaciones. De esta manera, refiriéndose al extravío o pérdida de los envíos, la Corte de Apelaciones de Antofagasta ha señalado que tanto la actividad como las indemnizaciones se encuentran reguladas en el Reglamento de Indemnizaciones para el Servicio de Encomiendas y Certificados, y en la Resolución Exenta 67 del Ministerio de Transportes y Telecomunicaciones, cuestión que permitiría excluir la aplicación de la LPC y, por consiguiente, la competencia de los Juzgados de Policía Local. ${ }^{22}$ De esta manera, se indicó: "Que conforme lo expuesto más arriba, efectivamente la actividad de prestación de servicios que realiza la apelante se encuentra regulada por leyes especiales y especificamente el Reglamento de Indemnizaciones para el Servicio de Encomiendas y Certificados del I2 de noviembre de 1968, que señala en su artículo 2: Cuando una encomienda postal se extravie, sufra averías o sea despojada de su contenido o parte de él, el remitente, o a falta de este destinatario, tendrá derecho a que el Servicio le cancele una indemnización equivalente al 50\% del monto de la pérdida, avería o despojo, comprobado mediante factura y hasta un $100 \%$ en casos es-

so Corte de Apelaciones de Santiago, 5 de octubre de 20I0, rol I287-20IO.

${ }^{51}$ Corte de Apelaciones de Valparaíso, I7 de noviembre de 2009, rol 608-2009. El caso restante, dictado por la Corte de Apelaciones de Valdivia, también rechaza la aplicación de la LPC. No obstante, el escaso desarrollo del fallo determina que este se asemeje a un supuesto de excepción impropia, a los que se aludía anteriormente. Corte de Apelaciones de Valdivia, 29 de enero de 2016, rol 236-2015.

s2 Corte de Apelaciones de Antofagasta, 20 de julio de 2007, rol 67-2007. 
peciales debidamente calificados por la Dirección y donde se establezca una responsabilidad directa del Servicio. Por último la Resolución Exenta 67 del Ministerio de Transportes y Telecomunicaciones de 30 de noviembre de 2005, señala en su artículo I, apartado II, Servicios de Encomienda Prefranqueada y Correos-TNT Mercado de Personas que cuando un envío Encomienda Prefranqueada o Correos TNT Personas se extravie, sufra averías o sea despojado de su contenido o parte de él, el remitente tendrá derecho a que la empresa le pague una indemnización equivalente a las siguientes sumas, según las variables que en cada caso se detallan, para a continuación colocarse en cuatro situaciones diversas. [...]

"Que conforme lo señalado, la situación que se denunció a fojas 9 y siguientes se encuentra regulada en una ley especial y por tanto excluida del ámbito de aplicación de la Ley 19.496 sobre Protección de los Derechos de los Consumidores y de la competencia del Juzgado de Policía Local, por lo que corresponde acoger la excepción de incompetencia invocada».

Dicho considerando fue reproducido unos años más tarde por la misma Corte..$^{53}$ Posteriormente, en una sentencia de io de marzo de 2009, la Corte de Apelaciones de Antofagasta rechazó la aplicación de la LPC, atendiendo no solo a la referida Resolución Exenta 67, sino también a Resolución Exenta 89 del 26 de diciembre de 2008 que crea y reglamenta el servicio postal denominado «Servicio Courrier de Correos de Chile y los

53 "Conforme a lo señalado en el motivo que antecede, fluye que la actividad de prestación de servicios que realiza la empresa de Correos de Chile si se encuentra regulada por leyes especiales, y, en el caso que nos ocupa, especificamente por el Reglamento de Indemnizaciones para el Servicio de Encomiendas y Certificados de fecha I2 de noviembre de 1968, que al texto en su artículo 2 señala cuando una encomienda postal se extravía, sufra averías o sea despojada de su contenido o parte de él, el remitente, o a falta de este el destinatario, tendrá derecho a que el Servicio le cancele una indemnización equivalente al 50\% del monto de la pérdida, avería o despojo, comprobado mediante factura y hasta en un 100\% en casos especiales, debidamente calificados por la Dirección y donde se establezca una responsabilidad directa del Servicio.

"Asimismo, la Resolución Exenta 67 del Ministerio de Transportes y Telecomunicaciones de 30 de noviembre de 2005, señala en su artículo I, apartado II, Servicios de Encomienda Prefranqueada y Correos-TNT Mercado de Personas que, cuando un envio de encomienda prefranqueada o Correos TNT personas se extravia, sufra averias o sea despojado de su contenido o parte de él, el remitente tendrá derecho a que la empresa le pague una indemnización equivalente a las sumas que, según las variables que en cada caso se detalla, para posteriormente señalar lo que sucede en cuatro situaciones diversas que allí se consignan.

"En consecuencia, la situación que fuera denunciada a fojas 6 de la presente causa, se encuentra regulada en un ordenamiento jurídico especial, de tal suerte entonces que no puede aplicarse a su respecto la Ley 19.496 sobre Protección de los Derechos de los Consumidores y de la Competencia del Juzgado de Policía Local, por lo que la excepción de incompetencia deberá ser acogida». Corte de Apelaciones de Antofagasta, 3 de marzo de 2009, rol 192-2008. 
Servicios Postales Adicionales de Courrier Nacional in AM»y «Courrier Nacional con Pago en Destino y Embalaje», 54 argumentando que la situación denunciada (extravío, avería o despojo parcial o total del contenido del envío) y la indemnización están reguladas por la ley especial.

La misma Corte, unos años más tarde, rechazó en dos oportunidades la aplicación de la LPC, atendida la regulación establecida en el mencionado Reglamento de Indemnizaciones para el Servicio de Encomiendas y Certificados y la Resolución Exenta 67 del Ministerio de Transportes y Telecomunicaciones. ${ }^{55}$

Al margen de que todos los pronunciamientos referidos sean de la misma Corte de Apelaciones, es importante destacar que el fundamento de la decisión descansa siempre sobre la suficiencia de la regulación especial en relación con el problema específico que se alega.

Ahora, eso no implica que siempre se rechace la aplicación de la LPC en materia de correos. En efecto, esta debe ser aplicada cuando el problema específico que se alega no se encuentra previsto en la normativa especial. De esta manera, la Corte de Apelaciones de Arica ha resuelto que no es posible excluir la aplicación de la normativa de protección al consumidor mediante la aplicación del Decreto Supremo 1507 del Ministerio del Interior, publicado en el Diario Oficial el 25 de noviembre de 1968, en cuanto este regula los casos de pérdida del envío, mas no de su retraso, indicando que «en tales condiciones, no puede sostenerse que la materia debatida en estos autos se encuentre en la situación prevista en el artículo 2 DEG bis de la Ley 19.496, es decir, excluida del ámbito de aplicación de la misma, sino que, por el contrario, al no existir ley especial que regule la infracción denunciada en la prestación de servicios efectuada por el Servicio de Correos de Chile, dicha ley le es plenamente aplicable, pues de otro modo el recurrente no tendría como satisfacer sus derechosm. ${ }^{56}$

\section{ConcLusión}

Este trabajo comienza asumiendo que la LPC constituye un supuesto de descodificación material y que el valor $-\mathrm{o}$, al menos, un valor- que permite hablar de descodificación material, en este caso, es la igualdad entre las partes. El Código Civil asume una noción de igualdad formal; en cambio, la LPC, al prestar atención a las condiciones materiales en las que,

${ }^{4}$ Corte de Apelaciones de Antofagasta, Io de marzo de 2009, rol I72-2008.

ss Corte de Apelaciones de Antofagasta, 29 de marzo de 20I2, rol I26-20II y Corte de Apelaciones de Antofagasta, 8 de marzo de 2013, rol 262-20I2.

${ }_{56}$ Corte de Apelaciones de Arica, I8 de abril de 20II, rol I4-20II. 
típicamente, se desenvuelven las relaciones de consumo, asume lo inverso, que las partes se encuentran en una posición de igualdad que permite a una abusar de la otra. La función de la LPC consiste en proteger a la parte que se encuentra en la posición menos favorecida.

Sugerimos que esa función podría verse amenazada por dos razones diversas. La primera de ellas es que otras leyes especiales tengan como derecho de referencia inmediata al Código Civil. La segunda es que, aun si dichas leyes tienen como ley general a la LPC en lo que refiere a la relación de consumo, contengan reglas incompatibles con esta, que devalúen la protección que prodiga la LPC a los consumidores.

Nuestra conclusión es que, al menos por el momento, ninguna de esas dos situaciones amenaza la descodificación lograda a través de la LPC. De una parte, no cabe duda que la LPC es la ley general de referencia inmediata respecto de otras leyes especiales que disciplinan ámbitos en los que se presentan relaciones de consumo. De otra parte, al examinar casos en que los tribunales han debido decidir si la presencia de una ley especial excluye o no la aplicación de la LPC, la respuesta predominante es no.

Por supuesto existen excepciones, algunas de ellas son únicamente aparentes pues corresponden a confusiones de los tribunales; otras, en cambio, obedecen a que el legislador de las leyes especiales ha establecido soluciones sustantivas o procedimentales diversas a las de la LPC. Según nos parece, entonces, al menos hoy resulta correcto afirmar que la calidad de consumidor provee de un estatuto de protección que se aplica con preferencia del derecho común y que, en general, no se ve afectado por leyes especiales.

Esta última conclusión evidencia la enorme importancia que tiene en Chile la LPC y, por lo mismo, los valores que procura materializar. Atendida la enorme frecuencia de la contratación de consumo, muy probablemente no haya exageración si se señala que, actualmente, junto a los clásicos principios generales del derecho de contratos - la autonomía privada y la buena fe- exista un tercero: la tutela de la parte más débil. Así como la autonomía privada se manifiesta con mayor vigor en las relaciones entre personas que se asumen en posición de igualdad, la tutela de la parte más débil cobra una enorme importancia en relaciones en las que esto típicamente no sucede. Es el caso del contrato de trabajo y de los contratos originados en relaciones de consumo. Esta última idea debiese ser el próximo paso en el estudio sobre el ámbito de aplicación de la Ley del Consumidor. 


\section{BibliografíA}

\section{Doctrina citada}

Aguirrezábal Grünstein, Maite, Comentario artículo so, en De la Maza, Ińigo y Pizarro, Carlos (directores), La protección de los derechos de los consumidores (Santiago, 2013, Legal Publishing).

Bordali-Salamanca, Andrés, La carga de la prueba en el proceso civil: una evolución desde la igualdad formal de las partes hacia una igualdad material de las mismas, en Revista de Derecho 23 (2016).

Corral, Hernán, La descodificación del Derecho Civil en Chile, en La descodificación del Derecho Civil en Chile, en El Código Civil de Chile (I855-2005). Trabajos expuestos en el Congreso Internacional celebrado para conmemorar su promulgación (Santiago, 3-6 de octubre de 2005), ahora en Guzmán Brito, Alejandro (editor), Lexis Nexis (Santiago, 2007).

DE la Maza Gazmuri, Ińigo, ¿Por qué el Estado y no solamente el mercado?, en Revista Chilena de Derecho Privado i (2003).

DE la Maza Gazmuri, Iñigo, ¿Respecto de qué?, en AA.VV., La desigualdad, Seminario en Latinoamérica de Teoría Constitucional y Política (Buenos Aires, 20i6, Libraria).

DE LA MAzA Gazmuri, Iñigo, Lex specialis: sobre el articulo 2 bis de la ley I9.496, en Revista de Derecho (Universidad de Concepción) 88 (2020).

Díez-Picazo, Luis, Fundamentos del Derecho Civil Patrimonial (Madrid, Civitas, 6. a edición, 2007) I.

Figueroa YáÑez, Gonzalo, Codificación, descodificación, recodificación del derecho civil (2005), en Cuadernos de Análisis Jurídicos, Colección de Derecho Privado II, Universidad Diego Portales, pp. IO5.

Fuenmayor, Amadeo, Alcance del principio constitucional de igualdad, en Anuario de Derecho Civil, 4 (I983) 36.

IrTI, Natalino, La edad de la descodificación (Editorial Bosch, s.l., I992).

Kemelmajer Carlucci, Aída, Los dilemas de la responsabilidad civil, en Revista Chilena de Derecho 28 (200I) 44.

Seco Martínez, José María, De la igualdad formal a la igualdad material. Cuestiones previas y problemas a revisar, en Derechos y Libertades: Revista de Filosofía del Derecho y Derechos Humanos 36 (enero 20I7).

Verónica López, Patricia, La tutela precontractual en la Ley 19.496: su configuración, alcance y eventual convergencia con aquella propia de la contratación civil, en Revista Chilena de Derecho, 2 (2019) 46.

Wahl Silva, Jorge, La protección de los derechos de los consumidores en Chile, Aspectos sustantivos y procesales luego de la reforma contenida en la Ley I9.955 de 2004, ahora en BARAONA, Jorge y LAgos, Osvaldo (editores), 
La protección de los derechos de los consumidores en Chile, Cuadernos de Extensión Jurídica I2 (Santiago, 2006, Universidad de los Andes, Facultad de Derecho).

Walker Silva, Nathalie, Bases para una deconstrucción del concepto de rescisión por lesión, en Revista Chilena de Derecho 44 (2017) 3, pp. 703-725.

\section{Jurisprudencia citada}

Tribunal Constitucional español de 25 de enero de 1983.

Corte de Apelaciones de Valparaíso, 22 de septiembre de 2004, rol II5572003.

Corte de Apelaciones de Valparaíso, 28 de diciembre de 2004, rol 56I2004.

Corte de Apelaciones de Santiago, 23 de marzo de 2005, rol 6175-2003.

Corte de Apelaciones de Santiago, I de julio de 2005, rol 5104-2005.

Corte de Apelaciones de Santiago, 07 de abril de 2006, rol 4792-2005.

Corte de Apelaciones de San Miguel, I3 de julio de 2006, rol I757-2004.

Corte de Apelaciones de Coyhaique, 20 de noviembre del 2006, Rol 222006.

Corte de Apelaciones de Antofagasta, 20 de julio de 2007, rol 67-2007.

Corte de Apelaciones de Puerto Montt, 16 de agosto de 2007, rol 2522007.

Corte de Apelaciones de Santiago, 5 de noviembre de 2007, rol 4205-2007.

Corte de Apelaciones de Coyhaique, 28 de febrero de 2008, rol 2-2008.

Corte Suprema, 2I de julio de 2008, rol 3023-2008.

Corte de Apelaciones de San Miguel, 04 de agosto de 2008, rol I04-2008.

Corte de Apelaciones de Antofagasta, 3 de marzo de 2009, rol 192-2008.

Corte de Apelaciones de Antofagasta, Io de marzo de 2009, rol 172-2008.

Corte de Apelaciones de Concepción, I7 de junio de 2009, rol 352-2008.

Corte de Apelaciones de Valparaíso, I7 de noviembre de 2009, rol 6082009.

Corte de Apelaciones de Copiapó, 23 de marzo de 20IO, rol 3-20Io.

Corte de Apelaciones de Santiago, 5 de octubre de 20IO, rol I287-20IO.

Corte de Apelaciones de La Serena, 3I de diciembre de 20I0, rol 86-20IO.

Corte de Apelaciones de Arica, I8 de abril de 20II, rol I4-20II.

Corte de Apelaciones de Antofagasta, io de junio de 20II, rol 63-20II.

Corte de Apelaciones de Chillán, 4 de julio de 20II, rol 34-20II.

Corte de Apelaciones de Copiapó, 7 de julio de 20II, rol 27-20II.

Corte de Apelaciones de Talca, I3 de julio de 20II, rol 4I3-20II.

Corte de Apelaciones de Antofagasta, I9 de marzo de 20I2, rol 235-20I4.

Corte de Apelaciones de Antofagasta, 29 de marzo de 20I2, rol I26-20II. 
Corte de Apelaciones de Valparaíso, I9 de julio de 20I2, rol I88-20I2. Corte de Apelaciones de La Serena, 3 de agosto de 20I2, rol I79-20II. Corte de Apelaciones de Concepción, 6 de diciembre de 20I2, rol 2682012.

Corte de Apelaciones de Antofagasta, 8 de marzo de 2013, rol 262-20I2. Corte de Apelaciones de Santiago, I6 de abril de 2013, rol IO28-20I2. Corte de Apelaciones de Santiago, 27 de agosto de 2013, rol 1327-20I2. Corte de Apelaciones de Santiago, I6 de agosto de 2013, rol 1678-20I2. Corte Suprema, 28 de octubre de 2013, rol 3978-2013.

Corte de Apelaciones de Valdivia, 3 de septiembre de 20I3, rol IIO-20I3. Corte de Apelaciones de Valdivia, I3 de septiembre de 2013, rol 165-2013. Corte de Apelaciones de Santiago, 30 de junio de 20I4, rol 265-20I4. Corte de Apelaciones de Valdivia, o7 de julio de 20I4, rol 5I-20I4. Corte Suprema, 23 de julio de 20I4, rol 9025-2013.

Corte de Apelaciones de Valparaíso, 2 de octubre de 20I4, rol 424-20I4. Corte de Apelaciones de Valdivia, I9 de noviembre de 20I4, rol 195-20I4. Corte de Apelaciones de Concepción, 9 de febrero de 2015, rol 235-20I5. Corte de Apelaciones de Coyhaique, 23 de abril de 20I5, rol 7-20I5. Corte de Apelaciones de Valparaíso, 4 de mayo de 20I5, rol IO4-20I5. Corte de Apelaciones de Antofagasta, 22 de julio de 20I5, rol I05-20I5. Corte de Apelaciones de Valparaíso, 24 de agosto de 20I5, rol 229-20I5. Corte de Apelaciones de Iquique, rol 39-2015, 28 de septiembre de 2015. Corte de Apelaciones de Talca, 6 de noviembre de 2015, rol 272-20I5. Corte de Apelaciones de Valdivia, I9 de noviembre de 2015, rol 179-2015. Corte de Apelaciones de Valdivia, 29 de enero de 2016, rol 236-2015 Corte Suprema, rol 7002-2015, is de mayo de 2016.

Corte de Apelaciones de Santiago, i de julio de 2016, rol 480-20I6. Corte de Apelaciones de Santiago, 8 de julio de 2016, rol 594-20I6. Corte Suprema, II de octubre de 2016, rol 4903-20I5.

Corte de Apelaciones de Antofagasta, 29 de diciembre de 2016, rol I572016.

Corte de Apelaciones de San Miguel, I7 de noviembre de 20I7, rol 9702017.

Corte Suprema, rol 62173-20I6, 2I de diciembre de 2017.

Corte Suprema, rol I00759-2016, 29 de noviembre de 2018. 


\section{ReCONOCIMIENTOS}

Este trabajo forma parte del Proyecto Fondecyt Regular iı80608, titulado «Ámbito de aplicación de la Ley 19.496: Diagnóstico, desafíos y perspectivas», del cual Ińigo de la Maza es investigador responsable.

Los autores agradecen a Boris Antonio Loayza Mosqueira y a Raimundo Norambuena Oyanedel, licenciados en Derecho de la Universidad Diego Portales, por su colaboración en la búsqueda y fichaje de sentencias en que se basa esta publicación.

\section{SOBRe LOS AUTORES}

ÍNigo de la MaZa GaZmuri es licenciado en Ciencias Jurídicas de la Universidad Diego Portales, Master in the Sciences of Law de la Universidad de Stanford y doctor en Derecho Privado de la Universidad Autónoma de Madrid. Su correo electrónico es inigo.delamaza@mail.udp.cl. (1) https:// orcid.org/oooo-oooi-6239-2837.

Hernán Cortez López es licenciado en Ciencias Jurídicas y magíster en Derecho Civil Patrimonial de la Universidad Diego Portales. Su correo electrónico es hernan.cortez@mail.udp.cl. (1) https://orcid.org/oooo0002-5530-8585. 
